\title{
POSSIBILIDADES DE UTILIZAÇÃO DOS RESÍDUOS DE ESTAÇÃO DE TRATAMENTO DE ÁGUA: ESTUDO DE CASO ETA-JF/MG
}

\author{
Roberta Paulina Tertolino da Silva ${ }^{(1)}$ (roberta.silva@arquitetura.ufjf.br), Sue Ellen Costa Bottrel ${ }^{(2)}$ \\ (sue.bottrel@ufjf.edu.br), Renata de Oliveira Pereira (renata.pereira@ufjf.edu.br) ${ }^{(3)}$ \\ (1) Universidade Federal de Juiz de Fora (UFJF). Programa de Pós-graduação em Ambiente Construído - Rua José Lourenço \\ Kelmer, s/n, sala 4156, São Pedro, Juiz de Fora/MG. \\ ${ }^{(2,3)}$ Universidade Federal de Juiz de Fora (UFJF). Departamento de Engenharia Sanitária e Ambiental - Rua José Lourenço Kelmer, \\ s/n, sala 4156, São Pedro, Juiz de Fora/MG.
}

RESUMO: A crescente demanda por água potável devido ao aumento populacional tem contribuído significativamente para ampliação dos resíduos produzidos nas estações de tratamento de água (ETA). Grande parte desse material gerado tem como destino os cursos d'água, impactando o meio ambiente. Este trabalho tem como objetivo realizar uma revisão sistemática sobre a geração de lodo de ETA no Brasil e alternativas para a destinação final visando o reúso apresentando um estudo de caso da ETA-JF. A metodologia foi baseada no mapeamento sistemático, tendo como fonte de pesquisa as plataformas de dados nacionais e internacionais. Os resultados obtidos forneceram uma reflexão sobre as opções de tratamento e o reaproveitamento de resíduos das ETAs, além de como avaliar a quantidade do volume gerado e dentre as alternativas verificar qual método seria mais eficiente. Conclui-se que a forma de reaproveitamento para a ETA em estudo poderá ser uma opção viável e que trará grandes benefícios ao meio ambiente.

PALAVRAS-CHAVE: Tratamento de Água, lodo de ETA, Aproveitamento de resíduos.

\section{INTRODUÇÃO}

Com o aumento da população urbana surge à demanda por serviços, produtos e bens, o que leva ao crescimento industrial. Como consequência a crescente geração de resíduos e a demanda por infraestrutura básica de saneamento. Sendo assim, a Estação de Tratamento de Água (ETA) se enquadra como setor industrial, compreendendo o operacional, o produtivo e o produto final que consiste no abastecimento público e geração de resíduo (Porras, Isaac e Morita, 2008).

Na ETA o líquido bruto passa por diversos tratamentos físicos, químicos e biológicos, antes de chegar ao consumidor (Coelho et al., 2015). O sistema de tratamento de água mais utilizado no Brasil é de ciclo completo, também chamado de tratamento convencional que compreende os processos de coagulação, floculação, decantação, filtração e desinfecção. Na etapa de coagulação e floculação, as impurezas contidas na água são aglutinadas formando flocos, sendo removidos nas etapas de decantação e filtração. Para algumas, ETAs os processos de decantação e filtração são substituídos pelo processo de floto-filtração, que ocorre em uma única unidade, o flotador. O processo final de desinfecção, inativam os microrganismos patogênicos, oxidam algumas substâncias químicas, sendo assim, o produto final, a água potável, chega ao consumidor com padrão necessário para o seu consumo (Wagner e Pedroso, 2014; Araújo e Silveira, 2017).

Desta forma, durante o tratamento da água são gerados resíduos: água de lavagem de filtros (ALAF) e os lodos gerados nos decantadores ou flotadores (Achon e Cordeiro, 2015).

Os produtos químicos utilizados nos processos podem conter principalmente compostos com base no alumínio, ferro, manganês e cromo, devendo ter o cuidado da disposição final do produto para evitar a poluição dos corpos receptores (Araújo e Silveira, 2017). Desta forma, o resíduo final 
gerado (lodo) possui propriedades diversas, conforme, a tecnologia empregada no tratamento da água, às condições da água bruta, quantidade e tipo de produtos químicos utilizados e da gestão dos resíduos, sendo a forma de extração, o tempo de acúmulo e o modo de limpeza dos locais determinantes na sua caracterização (Achon e Cordeiro, 2013; Andrade et al., 2014).

Conforme a NBR 10.004: 2004, o lodo da ETA é visto como resíduo sólido, classificado como não inerte de Classe II A. A legislação ambiental para os resíduos de ETA compreendem leis de crimes ambientais (Lei 9.605/1998) e a Política Nacional de Resíduos Sólidos (Lei 12.305/2010), estabelecendo crime o lançamento de resíduo direto em corpos d'água. Portanto, de acordo com a Lei 12.305/2010 os lodos (resíduos) de ETAs devem ser administrados com objetivo da minimização e tratamento, que compõe a redução, reuso e reciclagem (Achon e Cordeiro, 2013). Conforme a mesma lei, no capítulo II, inciso VII da destinação final ambientalmente adequada que compreende a reutilização, a reciclagem, a compostagem, a recuperação e o aproveitamento energético ou outras destinações admitidas pelos órgãos competentes.

Segundo Richter (2001), a destinação final do lodo da ETA para o prestador do serviço é um processo que apresenta custos elevados e restrições ao meio ambiente. Com isso, as alternativas mais usadas para o descarte do material, são: lançamento em cursos d'água, lançamento ao mar, lançamento na rede de esgoto sanitária, lagoas, aplicação ao solo e aterro sanitário.

No Brasil, o descarte do lodo da ETA ocorre em rios sem nenhum tipo de tratamento, levando a degradação dos mesmos, com aumento da concentração de sólidos, assoreamento, mudança de cor e turbidez, inibição das atividades biológicas, acúmulo de alumínio, ferro e outros elementos; além disso, prejudica a saúde humana (Wolff, Schwabe e Conceição, 2015). Conforme Paiva e Parreira (2012), a diminuição da quantidade de resíduos, o seu reaproveitamento e destino final correto, apresenta um dos grandes desafios para a indústria moderna, com a conscientização ecológica e leis que regularizam atividades que tragam impactos ambientais.

Diversos autores apresentam soluções e alternativas para a utilização do lodo, seja de forma parcial ou total do resíduo. Tsutiya e Hirata (2001) citam várias possibilidades da reutilização ou aproveitamento dos lodos, sendo disposição no solo, fabricação de cimento, fabricação de tijolos, cultivo de grama comercial, entre outros.

Diante das possibilidades de aproveitamento dos resíduos da estação de tratamento de água, é interessante classificar qual alternativa poderá trazer melhor benefício, uso de um volume maior do material, não prejudicando a qualidade técnica do elemento que esta sendo produzido e sem prejudicar o meio ambiente.

\section{OBJETIVO}

O objetivo do artigo é realizar uma revisão sistemática sobre a geração de lodo de ETA no Brasil e alternativas para a destinação final visando o reuso apresentando um estudo de caso da ETAJF.

\section{REFERENCIAL TEÓRICO}

\subsection{Resíduos}




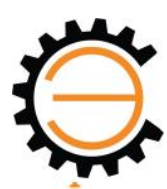

C E N

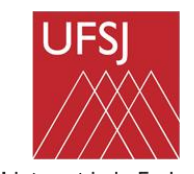

Universidade Federal de São João del-Rei

Conforme a norma NBR 10.004 (ABNT, 2004) os resíduos na forma de sólidos e semisólidos, de origem industrial, doméstica, hospitalar, comercial, agrícola, de serviços e de varrição. Incluídos nesta descrição os lodos provenientes de sistemas de tratamento de água, gerados em equipamentos e instalações de controle de poluição são considerados resíduos sólidos.

Neste caso, os resíduos de ETA, são classificados como da classe II A - não inerte, sendo que o mesmo não poderá ser lançado diretamente em corpo d'água, sem nenhum tipo de tratamento adequado, por ter como consequências diretas ao meio ambiente e os seres vivos que nele habitam.

Conforme dados do SIDRA (2010), os lodos são lançados em diversos tipos de sistemas, sendo a maioria descartado nos rios de forma incorreta, infringindo Leis Ambientais de diversas áreas. Como verificado na Figura 1, 67,5\% do lodo são lançados em rios e apenas 2,4\% é reaproveitado, para o caso do Brasil, percentual este muito baixo para um resíduo que apresenta impacto ambiental. Outra forma de disposição final do lodo no Brasil seria aterro sanitário com 4,5\%. Para o material ser descartado em aterros sanitários é importante ter padrão e parâmetros, não ser classificado com resíduo perigoso e não apresentar líquidos livres na composição (Andrade, 2005). Assim, é preciso desidratá-lo para obter o teor de sólido entre 20\% a 25\% (Richter, 2001).

Com relação à disposição final do lodo de ETA na esfera internacional (Figura 1), verifica-se que a maior parte se encontra em aterro sanitário e lançamento em sistema de esgoto. Contudo, ao analisar os países, tem-se: Holanda com 51\% em estocagem devido ao alto teor de arsênio presente no mesmo, Reino Unido com 52\% em aterro sanitário, França com 53\% em outros destinos e Estados Unidos com $25 \%$ de reúso no solo.

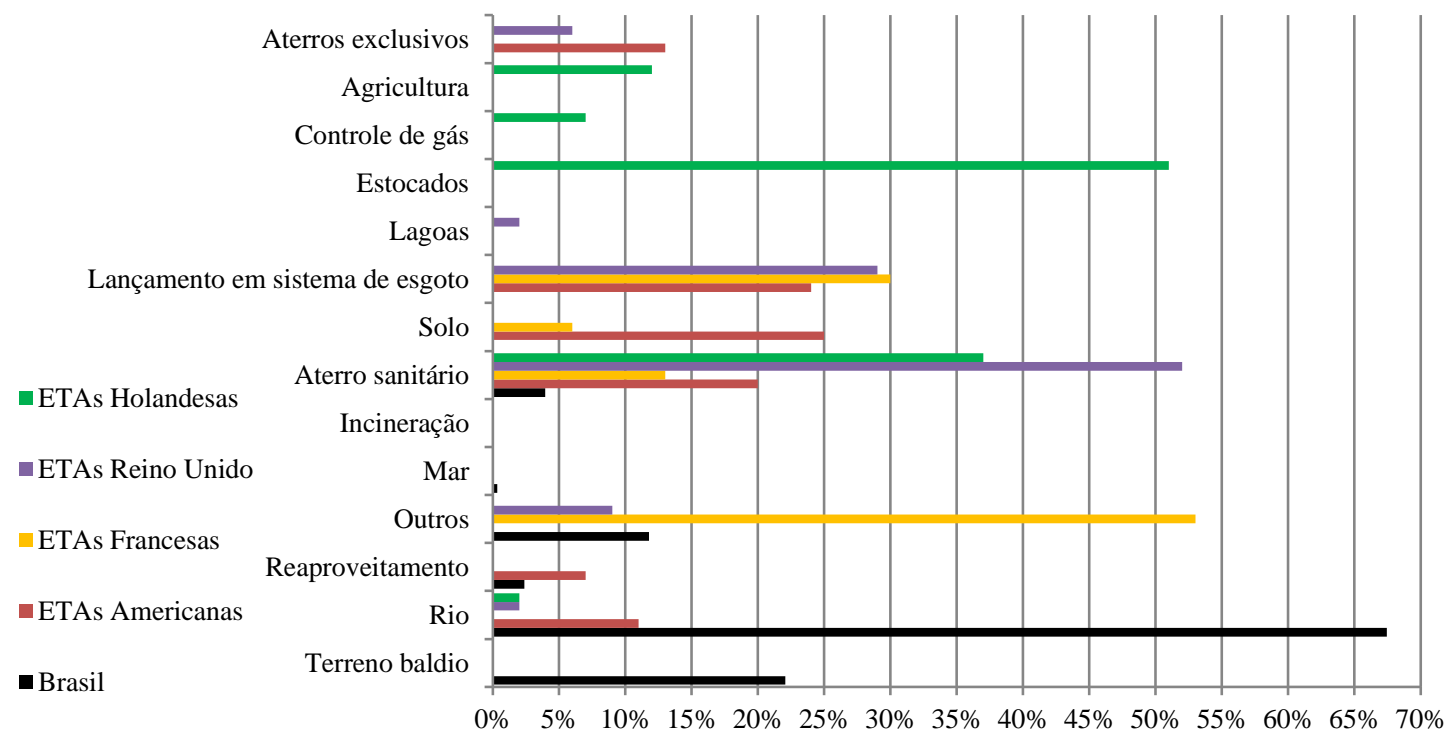

Figura 1. Destino do lodo da ETA gerada no Brasil e no mundo

Fonte: SIDRA ${ }^{1}$, Pesquisa Nacional de Saneamento Básico, atualizado em 20/08/2010 e Andrade, 2005. Adaptado.

\footnotetext{
${ }^{1}$ Sidra - Sistema IBGE de Recuperação Automática. Obtenção gratuita dos dados agregados de estudos e pesquisas realizados pelo IBGE. Disponível em: https://sidra.ibge.gov.br/Tabela/1755
} 


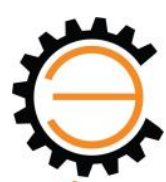

C $\mathrm{EN}$

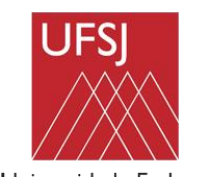

Universidade Federal de São João del-Rei

\section{MATERIAIS E MÉTODOS}

Neste trabalho foi realizada uma revisão da literatura com busca em livros, normas, trabalhos científicos e artigos científicos selecionados através de bases de dados. Além disso, realizou-se um estudo de caso de uma ETA.

\subsection{Revisão sistemática da literatura}

A metodologia aplicada à pesquisa foi revisão de literatura baseado no mapeamento sistemático, que segundo Kitchenham e Charters (2007) fornece ampla visão de estudos primários em uma determinada área, visando identificar quais evidências estão disponíveis sobre o tópico.

Para a pesquisa utilizou-se as seguintes bases de dados nacionais e internacionais: Portal de Periódicos CAPES/MEC, Google Acadêmico, SCielo e Science Direct. Para a busca nas plataformas foram adotados os seguintes critérios de palavras-chave relacionadas com o tema pesquisado: Estação de Tratamento de Água (ETA), Resíduo AND Estação de Tratamento de Água, Lodo AND Estação de Tratamento de Água, Descarte AND Lodo da Estação de Tratamento de Água;Water treatmentstation, Wastewater Treatment Station, Water Treatment Plant Sludge e Destination of Water Treatment Plant Sludge. Para a seleção dos artigos, primeiro foram verificados o título, o resumo e as palavras-chave; em seguida escolhidos os mais expressivos para a pesquisa, sendo retirados artigos duplicados.

Com a estratégia adotada para os levantamentos de dados têm-se os resultados apresentados na Tabela 1, de acordo com as palavras-chave adotadas. No Google Acadêmico e na Plataforma Science Direct foi necessário fazer o filtro de período específico de 2015 a 2019. Após a seleção de interesse permaneceram 82 artigos para a discussão dos resultados.

Tabela 1. Quantidade de artigos levantados pelas palavras-chave nas diferentes bases

\begin{tabular}{ccc}
\hline Número de artigos & Nacional & Internacional \\
\hline Número Total de artigos & 2551 & 235 \\
\hline Total sem repetição de título & 142 & 225 \\
\hline Total relevante à pesquisa & 62 & 20 \\
\hline
\end{tabular}

Fonte: Autoria Própria

\subsection{Caracterização da área de estudo}

Para o estudo de caso foi considerada uma ETA da cidade de Juiz de Fora, MG (ETA-JF) que recebe água do Ribeirão do Espírito Santo, produz $620 \mathrm{~L} / \mathrm{s}$, abastecendo aproximadamente $40 \%$ da população da cidade. A captação no Ribeirão do Espírito Santo é praticada diretamente no leito do curso d'água não tendo barragem de reserva. A bacia do Ribeirão do Espírito Santo tem uma área de $147,8 \mathrm{Km}^{2}$, e boa parte localiza-se na zona rural, a noroeste do município de Juiz de Fora (CESAMA, 2019; Plano de saneamento básico, 2013).

A ETA pesquisada apresenta as seguintes etapas de tratamento de água: captação, coagulação, floculação, decantação, filtração, fluoretação e cloração, que consiste no tratamento de ciclo completo (Pereira, Gomes e Pereira, 2012). Segundo dados da pesquisa de Sousa et al. (2014) e Ferreira et al. (2017), a ETA- JF utiliza o coagulante Floculan (sulfato ferroso clorado), apresenta densidade do lodo $1.009 \mathrm{~kg} / \mathrm{m}^{3}$, densidade do lodo seco $1.800 \mathrm{~kg} / \mathrm{m}$, produção de sólidos de $5 \mathrm{Ton} / \mathrm{dia}$ e 

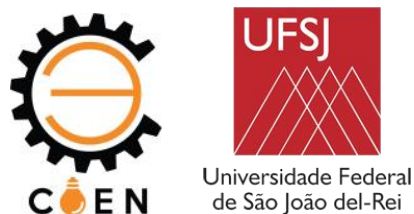

concentração de sólidos $2 \%$. A ETA opera com dois decantadores com cerca de $1.609 \mathrm{~m}^{3}$ cada e a lavagem é realizada de forma manual.

\subsection{Quantidade de resíduos gerados, reaproveitamento e destinação final.}

A ETA-JF conforme a pesquisa de Oliveira (2015), apresenta um teor de sólidos totais do lodo com média de $101 \mathrm{~g} / \mathrm{L}$. E com base na pesquisa de Pereira, Gomes e Pereira (2012), que tem como resultado de produção mensal de sólidos correspondente a $161.456 \mathrm{~kg} / \mathrm{mês}$ maior valor (dezembro), $46.806 \mathrm{~kg} /$ mês menor valor (junho) e a média dos meses corresponde a $82.975 \mathrm{~kg} / \mathrm{ano}$.

A título de comparação da quantidade de lodo produzido por outras ETAs, foram investigadas outras 8 estações, conforme Tabela 2 que apresentava o quantitativo de produção nos artigos estudados. Entre as ETAs estudadas foi realizada uma comparação entre vazão e o quantitativo de resíduos gerados por ano.

Para saber o volume que representa o lodo da ETA e o possível destino, foi considerado o transporte realizado por caminhão a vácuo com sucção, esse por sua vez, tem capacidade variável que poderá ser de 8 a $16 \mathrm{~m}^{3}$. Neste caso, foi adotado o volume de $16 \mathrm{~m}^{3}$ para a coleta do lodo.

Através da avaliação dos artigos selecionados foi possível analisar o tipo de tratamento de dos lodos em ETAs e a forma de disposição final. Sendo assim, foram agrupados por tipo de tratamento e disposição final apresentando de forma sucinta suas vantagens e desvantagens. O propósito é obter uma visão ampla do assunto e ao final verificar qual poderá ter melhores resultados para aplicação do lodo de modo a minimizar o impacto ambiental e favorecer seu uso.

Portanto para o estudo de caso ETA-JF, escolheram-se algumas alternativas com base na distância, vantagens e desvantagens de acordo com a revisão bibliográfica e possibilidade de ter uma indústria que fabrica o material próximo a ETA. Através do Google Earth mediu-se a distância, estabelecendo um raio de $6.700 \mathrm{~m}$, neste círculo foram localizados possíveis lugares que poderiam receber o lodo.

\section{RESULTADOS E CONCLUSÕES}

\subsection{Quantidade de lodo gerado na ETA}

De acordo com a pesquisa de Pereira, Gomes e Pereira (2012), sobre a estimativa de lodo produzido na ETA-JF, foram trabalhados os resultados de médias mensais de turbidez e produção de sólidos totais do ano de 2010. As autoras observaram uma diferença de $40 \%$ na produção de sólidos nos períodos chuvosos e de estiagem. É importante anotar essa diferença para buscar o melhor destino do resíduo, principalmente no período com maior volume. A produção de sólidos que ocorreu na ETA, para o valor mínimo no mês de junho foi de 47 toneladas e o valor máximo no mês de dezembro de 161 toneladas, todo esse material é despejado diretamente no corpo d'água. No levantamento do ano de 2010 a produção de sólidos totais correspondeu a 913 toneladas, o que representaria 56 caminhões que levariam esse material a um destino específico.

$\mathrm{Na}$ Tabela 2 verifica-se o uso de três tipos de coagulante diferentes para a etapa de tratamento da água, além disso, podem ser utilizados outros produtos químicos como parte do processo. Com relação à capacidade de cada ETA, percebe-se que existe uma diferença grande entre elas, isso seria de acordo com a população abastecida. Não houve correlação entre a vazão da ETA e o volume anual 
de lodo gerado, possivelmente devido a características da qualidade da água, produtos químicos utilizados e forma de operação. Contudo, se retirarmos as duas maiores vazões de 1000 e $3500 \mathrm{~L} / \mathrm{s}$ encontra-se uma correlação positiva com $\mathrm{R}^{2}=0,92$ e equação de $\mathrm{y}=1529 \mathrm{x}-10073$ (sendo $\mathrm{x}$ a vazão $\mathrm{e}$ y a produção em $\mathrm{Kg} /$ ano de resíduos). Portanto, há características semelhantes e estudos nessa linha podem ser aprofundados.

Como forma de tratamento do lodo, a maioria não apresenta o destino correto do resíduo, apenas a ETA Rio Manso, com a UTR que segundo Paiva e Parreira (2012), foi criada com o objetivo de recuperar e reutilizar as águas das lavagens de filtros e dos decantadores. Nessa ETA, após o tratamento a água clarificada é recirculada e o resíduo adensado é encaminhado para lagoas onde após secagem natural, é retirado e disposto em aterro controlado (Guimarães e Pádua, 2005).

A capacidade da ETA B é a metade de A e mesmo assim ela tem um volume muito maior de lodo (Tabela 2), isto, segundo Oliveira e Rondon (2016) é devido a poluição e o assoreamento dos seus mananciais que demandam maior quantidade de produtos químicos, levando a maior quantidade de resíduo. A ETA-JF apresenta a vazão próxima da ETA B, verificando o volume de lodo gerado existe uma diferença de $35 \%$, como a capacidade da ETA-JF é um pouco maior, o volume ao final das duas ficaria próximo, pensando na equivalência das vazões entre as mesmas. Para se obter um resultado mais preciso de comparação entre as estações seria necessário maior número de dados.

Tabela 2. Levantamentos de algumas ETAs convencional no Brasil.

\begin{tabular}{ccccccc}
\hline ETA & $\begin{array}{c}\text { Coagul } \\
\text { ante }\end{array}$ & $\begin{array}{c}\text { Capacida } \\
\text { de (L/s) }\end{array}$ & $\begin{array}{c}\text { Volume } \\
\text { anual lodo } \\
\text { gerado } \\
\text { Kg/ano) }\end{array}$ & Lodo tratado & $\begin{array}{c}\text { Tipo de } \\
\text { decantador }\end{array}$ & Referência \\
\hline A & PAC & 1.000 & 381.408 & Parcialmente* & Alta taxa & $\begin{array}{c}\text { Oliveira e Rondon } \\
(2016)\end{array}$ \\
\hline B & PAC & 500 & 674.583 & Parcialmente & Alta taxa & $\begin{array}{c}\text { Oliveira e Rondon } \\
(2016)\end{array}$ \\
\hline Rio Manso & SA & 3.500 & 121.080 & UTR** & Convencional & $\begin{array}{c}\text { Guimarães e Pádua. } \\
(2005)\end{array}$ \\
\hline Itabirito & SA & 120 & 171.900 & Não tratado & Convencional & Ribeiro (2007) \\
\hline UFLA & CF & 9,4 & 4.896 & Não tratado & $\begin{array}{c}\text { Escoamento } \\
\text { vertical }\end{array}$ & Rodrigues (2015) \\
\hline $\begin{array}{c}\text { Porto das } \\
\text { Caixas }\end{array}$ & SA & 260 & 181.620 & Não tratado & - & Cruz (2018) \\
\hline $\begin{array}{c}\text { ETA 003 }- \\
\text { TO }\end{array}$ & SA & 100 & 75.040 & Não tratado & Alta taxa & Paz et al. (2018) \\
\hline $\begin{array}{c}\text { Campo } \\
\text { Mourão-PR }\end{array}$ & SA & 180 & 11.364 & Não tratado & Placas & $\begin{array}{c}\text { Almeida, Carvalho e } \\
\text { Passig. (2010) }\end{array}$ \\
\hline ETA-JF & FLO & 620 & 912.726 & Não tratado & Convencional & Pereira et al. (2012) \\
\hline
\end{tabular}

Fonte: Autoria Própria PAC: Policloreto de alumínio; SA: Sulfato de alumínio; CF: Cloreto Férrico; FLO: Floculan; Utilizado d=1.009 Kg/m³ conversão de unidades; * Parcialmente: uma parte do lodo não é lançado in natura nos cursos d'água; **UTR - Unidade de Tratamento de Resíduos - composta por decantadores secundários, adensadores e lagoa de secagem.

Portanto é importante investigar o gerenciamento e volume de lodo gerado nas ETAs, para assim, poder planejar e definir metas de uso e destinação correta dos resíduos, de acordo com as leis 

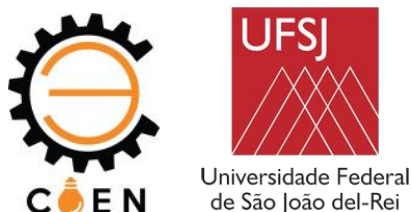

vigentes. Visto que, 67\% das ETAs analisadas na Tabela 2 não tratam seus resíduos e 2 tratam parcialmente. Fato este condizente com a revisão de literatura realizada (Figura 1).

\subsection{Estudo do reaproveitamento e destinação final do lodo da ETA}

Para ter um aproveitamento do lodo é necessário escolher o método levando em consideração a região, o transporte e o meio que será inserido o lodo conforme pode ser verificado na Tabela 3. Analisando a Tabela 3 verifica-se, por exemplo, que o lançamento em ETE e aterro podem ser uma boa opção, sendo já utilizado por outros países (Figura 1). Entretanto, deve-se atentar para a distância dos locais e a transferência do problema. Ou seja, a diminuição da vida útil do aterro e aumento da produção do lodo da ETE. Contudo, se os locais forem projetados para o recebimento destes materiais, com as considerações de maior volume os mesmos terão a capacidade de suportar tal aumento. Todavia, não haverá o reúso do lodo de ETA.

Uma forma de diminuir o volume do lodo seria o método de incineração e adensamento, ambos uma boa alternativa, porém tem desvantagens em relação ao custo de equipamento e desidratação do material, que, segundo Januário e Filho (2007) para incineração do lodo de ETA custaria por tonelada $\mathrm{R} \$ 2.000,00$. Além disso, teria que destinar corretamente a sobra das cinzas geradas no processo. Outro fator, que encareceria é o transporte do material até a usina, sendo assim, combinação desses métodos se tornam inviáveis para o descarte do lodo.

Alternativas do uso do lodo como parte, de agregado em materiais na construção civil, tornase interessante. No entanto a adição do lodo em alguns casos não poderá ultrapassar 5\%, para não prejudicar a qualidade técnica do produto. Mesmo com pouca adição, se tiver empresa próxima para receber o material, torna-se uma alternativa viável. No caso, para aplicação em material cerâmico é uma alternativa interessante, já que poderá ser aplicado até $20 \%$ do lodo. Segundo Oliveira (2017), a adição do lodo à argila poderá aumentar a vida útil das jazidas sem comprometer a qualidade do produto, mas também deve-se atentar para a proximidade da indústria.

O lodo no uso da disposição no solo ou áreas degradadas apresentam mais desvantagens do que vantagens podendo acarretar em problemas ambientais sem melhoras significativas do seu uso. Por outro lado, à produção de mudas com a porcentagem até $50 \%$ do lodo parece viável, principalmente se a localização do viveiro estiver próxima a ETA.

Além dessas possibilidades apresentas na Tabela 3, existem outras diversas forma de tratamento e utilização, a saber: recuperação e reutilização do sobrenadante do lodo do decantador, recirculação da água de lavagem de filtro, otimização das dosagens de coagulante, utilização de bypass para filtração direta, lançamento direto em águas superficiais, lançamentos em lagoas, disposição em leito de secagem, utilização de manta geotêxtil, revestimento rodoviário, substituição parcial de cimento, produção de geopolímeros e incorporação de materiais da construção civil, como exemplificados na pesquisa de Santos et al. (2018), Paiva, Moreira e Soares (2016) e Ribeiro (2007).

Dentre as alternativas apresentadas é observado que existem vários caminhos para utilizar o lodo, com custo maior, por exemplo, a incineração ou menor custo, como complemento de outros materiais e podendo ser viáveis como em planta de viveiro, confecção de materiais para construção civil e lançamento em ETE, devendo ter o cuidado da quantidade a ser adicionada no produto ser viável. O que não seria recomendado é a disposição em solo, pois compromete a fertilidade e em altas concentrações poderá causar a salinidade. Qualquer que seja o destino final do lodo deve-se analisar a região, a quantidade de volume gerado e a alternativa que cause menos impacto. 
Tabela 3. Tipos de tratamento e utilização de resíduos de lodo.

\begin{tabular}{|c|c|c|c|}
\hline $\begin{array}{c}\text { Tipo de } \\
\text { tratamento }\end{array}$ & Vantagem & Desvantagem & Referências \\
\hline $\begin{array}{l}\text { Adensamento } \\
\text { / Desidratação }\end{array}$ & $\begin{array}{l}\text { Faixa do teor de sólidos adensado todos } \\
\text { com adição de polímero: } \\
\text { - adensado por gravidade: } 3,5 \% \text { a } \\
4,73 \% \text {, } \\
\text { - espessamento por flotação: } 7,10 \% \\
\text { - adensamento mecânico: } 3,06 \% \text { a } \\
3,79 \% \\
\text { - desidratação por filtro prensa de } \\
\text { esteira: } 15,8 \% \text { a } 18,53 \%\end{array}$ & $\begin{array}{l}\text { - Maiores custos devido aos } \\
\text { equipamentos mecânicos. } \\
\text { - Dificuldade de controlar a } \\
\text { relação massa de polímero e } \\
\text { massa de sólido. } \\
\text { - Dosagem certa para melhores } \\
\text { resultados. }\end{array}$ & $\begin{array}{l}\text { Lopes e Serra } \\
\text { (2016); } \\
\text { Mendes, Filho e } \\
\text { Scian (2001); } \\
\text { Patrizzi, Reali e } \\
\text { Cordeiro (1999); } \\
\text { Souza (2001) }\end{array}$ \\
\hline $\begin{array}{l}\text { Incineração/s } \\
\text { ecagem } \\
\text { térmica }\end{array}$ & $\begin{array}{l}\text {-Redução de até } 85 \% \text { do peso e até } 95 \% \\
\text { do volume. } \\
\text { - Uso do resíduo em cobertura para } \\
\text { aterros e matéria-prima na construção. } \\
\text { - Independe das características } \\
\text { climáticas. } \\
\text { - Área de implantação é menor do que o } \\
\text { sistema de secagem natural. }\end{array}$ & $\begin{array}{l}\text { - Tratamento caro. } \\
\text { - Tratamento do material } \\
\text { particulado e gazes nocivos. } \\
\text { - Indicado para grandes volumes } \\
\text { > 2.250 Ton/ano. } \\
\text {-Secagem térmica: } 20 \text { a } 35 \% \text { de } \\
\text { sólidos. }\end{array}$ & $\begin{array}{l}\text { Margem } \\
\text { (2008);Januário e } \\
\text { Filho (2007); } \\
\text { Rubim (2013); } \\
\text { Paz (2007); } \\
\text { Montibeller e } \\
\text { Girardi (2018) }\end{array}$ \\
\hline $\begin{array}{l}\text { Disposição no } \\
\text { solo } \\
\text { degradado ou } \\
\text { solos como } \\
\text { adubo }\end{array}$ & $\begin{array}{l}\text {-Eleva os teores de macronutrientes e o } \\
\text { pH do solo e aumento de } \mathrm{Mn} \text {. } \\
\text { - Imobilização de } \mathrm{Al} \text { trocável. } \\
\text { - Possui elevada fertilidade pelo índice } \\
\text { de saturação de bases cerca de } 85 \% \text {, } \\
\text { apresenta diferentes afinidades por } \\
\text { elementos metálicos. Aumento do teor } \\
\text { de Cu. } \\
\text {-O lodo aplicado ao solo em diferentes } \\
\text { volumes, não variou os teores de Cu e } \\
\text { Pb. } \\
\text {-Concentrações de } \mathrm{Ca}^{2+} \text { e } \mathrm{Mg}^{2+} \\
\text { aumentaram conforme quantidade de } \\
\text { lodo. }\end{array}$ & $\begin{array}{l}\text {-Pode causar a salinidade do } \\
\text { solo. } \\
\text { - Uso associado a um resíduo } \\
\text { orgânico. } \\
\text {-Presença de metais pesados no } \\
\text { lodo pode limitar o uso. } \\
\text { - As dosagens aplicadas } \\
\text { suplantaram os limites das } \\
\text { substâncias inorgânicas. } \\
\text {-Não atingiram a concentração } \\
\text { boa de fertilidade do solo. }\end{array}$ & $\begin{array}{l}\text { Teixeira, Melo e } \\
\text { Silva (2005); } \\
\text { Paz (2007); } \\
\text { Moreira et al. } \\
\text { (2009); } \\
\text { Botero et al. } \\
\text { (2009); } \\
\text { Oliveira et al. } \\
\quad \text { (2015); } \\
\text { Ferreira et al. } \\
\text { (2017) }\end{array}$ \\
\hline $\begin{array}{l}\text { Lançamentos } \\
\text { na rede de } \\
\text { estação de } \\
\text { tratamento de } \\
\text { esgotos }\end{array}$ & $\begin{array}{l}\text {-Não influenciou na remoção de } \\
\text { nitrogênio e não causou impactos } \\
\text { negativos a ETE. } \\
\text {-Lodo adensado na ETE não é } \\
\text { prejudicial } \\
\text {-Para a DQO e nitrogênio não teve } \\
\text { alterações significativas na ETE. } \\
\text { - Contribuiu na eficiência do tratamento } \\
\text { da fase líquida na ETE. } \\
\text {-Lodo de ETA com 2g/L pode ser } \\
\text { lançado no adensador por gravidade da } \\
\text { ETE. }\end{array}$ & $\begin{array}{l}\text { - Alterou a qualidade } \\
\text { do tratamento de esgoto bruto. } \\
\text { - Aumento da concentração } \\
\text { de DBO e concentração de ferro } \\
\text { aumentou no lodo da ETE. } \\
\text { - Levou ao aumento da } \\
\text { concentração da DBO, sólidos, } \\
\text { fósforo (50\% de aumento) e } \\
\text { ferro total (5 vezes maior). }\end{array}$ & $\begin{array}{l}\text { Peixoto (2008). } \\
\text { Pereira (2011). } \\
\text { Marguti (2012). } \\
\text { Marguti, Ferreira } \\
\text { Filho e Piveli } \\
\text { (2018). }\end{array}$ \\
\hline
\end{tabular}


Tabela 3. Tipos de tratamento e utilização de resíduos de lodo.

\begin{tabular}{|c|c|c|c|}
\hline $\begin{array}{c}\text { Tipo de } \\
\text { tratamento }\end{array}$ & Vantagem & Desvantagem & Referências \\
\hline $\begin{array}{l}\text { Disposição em } \\
\text { aterros } \\
\text { sanitários }\end{array}$ & $\begin{array}{l}\text {-Compressão simples a resistência não- } \\
\text { drenada do lodo cresce } \\
\text { exponencialmente com o teor de } \\
\text { sólidos. } \\
\text { - Manutenção do pH a valores próximos } \\
\text { à faixa neutra. } \\
\text {-Secagem do lodo por um período de } 15 \\
\text { dias para obter teor de sólido de } 80 \% \text {. } \\
\text {-Coeficiente de permeabilidade menor } \\
\text { para traço de 1:0,5 (solo argiloso e lodo) } \\
\text { retém o percolado. }\end{array}$ & $\begin{array}{l}\text { - Necessidade de secar bem o } \\
\text { material. } \\
\text { - Adição de } 64 \% \text { de Lodo, } \\
\text { ocorreu aumento de } \mathrm{Al}, \mathrm{Fe}, \mathrm{Mn}, \\
\text { pH e sólidos. } \\
\text { - Distância poderá ter um custo } \\
\text { elevado. } \\
\text { - Teor adequado do lodo acima } \\
\text { de } 25 \% \text {. }\end{array}$ & $\begin{array}{l}\text { Bidone, Silva e } \\
\text { Marques (2001). } \\
\text { Silveira, Koga e } \\
\text { Kuroda (2013). } \\
\text { Paz (2007). } \\
\text { Gonçalves, et al. } \\
\text { (2017). } \\
\text { Silva e Hemsi } \\
\text { (2018). }\end{array}$ \\
\hline $\begin{array}{l}\text { Produção de } \\
\text { tijolo solo- } \\
\text { cimento }\end{array}$ & $\begin{array}{l}\text {-Deve ser utilizado de } 3 \% \text { a } 5 \% \text { de } \\
\text { resíduos de ETA. } \\
\text {-A quantidade de cimento, cal e areia } \\
\text { foram o mesmo } 10 \%, 6 \% \text { e } 40 \% \text {, o que } \\
\text { variou foi o lodo }(3,5,8 \text { e } 10 \%) \text { e solo } \\
(41,39,36334 \%) \text {. } \\
\text { Incorporação de resíduo (lodo) a } 900^{\circ} \text { e } \\
\text { lodo seco, o material apresenta } \\
\text { resistência e absorção para o tijolo solo- } \\
\text { cimento. }\end{array}$ & $\begin{array}{l}\text {-Limite de liquidez superior à } \\
\text { norma, o material sozinho não } \\
\text { pode ser utilizado. } \\
\text {-Resistência à compressão não } \\
\text { foi atingido. } \\
\text {-Reuso do lodo é limitado. } \\
\text {-Traço > 7,5\% não possui } \\
\text { consistência para formação de } \\
\text { bloco na prensa manual. }\end{array}$ & $\begin{array}{l}\text { Silva (2009). } \\
\text { Rodrigues e } \\
\text { Holanda (2013). } \\
\text { Rodrigues (2015). } \\
\text { Martins, et al. } \\
\text { (2016). } \\
\text { Cordeiro (2018). }\end{array}$ \\
\hline $\begin{array}{l}\text { Incorporação } \\
\text { do lodo em } \\
\text { painel de } \\
\text { madeira }\end{array}$ & $\begin{array}{l}\text { - Densidade média: adição de } 20 \% \text { e } \\
30 \% \text { próximas da média de } 500 \mathrm{~kg} / \mathrm{m}^{3} \text {. } \\
\text { - Boa absorção de água } \\
\text { - Inchamento de espessura: menor que } \\
8 \% \text { em } 2 \mathrm{~h} \text {, para } 6 \text { amostras, conforme } \\
\text { norma. } \\
\text { - O melhor tratamento foi para painel } \\
\text { com adição de } 30 \% \text { de lodo e } 16 \% \text { de } \\
\text { resina. }\end{array}$ & $\begin{array}{l}\text {-Densidade abaixo da norma. } \\
\text {-Teor de umidade acima da } \\
\text { norma } \\
\text {-Inchamento em espessura. } \\
\text {-Perfil irregular da superfície. }\end{array}$ & $\begin{array}{l}\text { Silva, et al.( 2014). } \\
\text { Silva, et al. (2015) }\end{array}$ \\
\hline $\begin{array}{l}\text { Muda em } \\
\text { viveiro }\end{array}$ & $\begin{array}{l}\text { - A substituição de terra por lodo não } \\
\text { interferiu no desenvolvimento radicular. } \\
\text { - Concentração de até } 50 \% \text { do lodo. } \\
\text { - Substrato com } 100 \% \text { de lodo } \\
\text { apresentou maior crescimento em altura } \\
\text { das mudas. } \\
\text { - Resultado: comprimento da raiz para a } \\
\text { amostra com } 50 \% \text { de solo, } 10 \% \text { de } \\
\text { esterco e } 40 \% \text { lodo foi maior. }\end{array}$ & $\begin{array}{l}\text {-Adição de } 75 \% \text { (lodo) e } 25 \% \\
\text { (substrato), mudança de } \\
\text { coloração da planta, menor teor } \\
\text { de clorofila e maior quantidade } \\
\text { de biomassa. } \\
\text {-Taxa de crescimento diminui } \\
\text { com o tempo. }\end{array}$ & $\begin{array}{l}\text { Neto (2011). } \\
\text { Rocha, et al. (2015). } \\
\text { Augusto (2016). } \\
\text { Ferreira, et al. } \\
\text { (2018). } \\
\text { Cruz (2018). }\end{array}$ \\
\hline $\begin{array}{l}\text { Produção de } \\
\text { material } \\
\text { cerâmico }\end{array}$ & $\begin{array}{l}\text { - Adição de } 25 \% \text { de resíduo. } \\
\text { - } 4 \% \text { de lodo não prejudica a função } \\
\text { estrutural. } \\
\text { - Bons resultados para: } 64 \% \text { argila, } 16 \% \\
\text { de sílica de casca de arroz e } 20 \% \text { de } \\
\text { lodo. }\end{array}$ & $\begin{array}{l}\text { - Amostra com apenas lodo } \\
\text { apresentou fissuração e flexão. } \\
\text { - } 50 \% \text { de sílica e } 50 \% \text { de lodo } \\
\text { teve problemas de estabilidade } \\
\text { microestrutural e degradação } \\
\text { espontânea. }\end{array}$ & $\begin{array}{l}\text { Wolff, Schwabe e } \\
\text { Conceição (2015). } \\
\text { Paiva, Moreira e } \\
\text { Soares (2016). } \\
\text { Oliveira (2017). }\end{array}$ \\
\hline
\end{tabular}

Fonte: Autoria Própria 


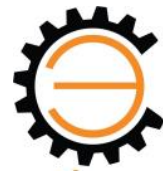

C E N

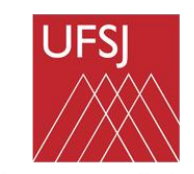

Universidade Federal de São João del-Rei

Portanto considerando as opções discutidas mediante disposição final do lodo, os métodos interessantes para a ETA-JF, seriam o lançamento em ETE, aterro sanitário, confecção de tijolo e disposição em viveiro. Outra alternativa viável que também poderia ser adotado é a produção de material cerâmico, no entanto, esse método não foi escolhido, porque para a cidade de Juiz de Fora não tem indústria na proximidade da ETA.

De acordo com a Tabela 4, a avaliação da distância da ETA-JF ao local de destino, o melhor caminho seria o aterro sanitário $(2,81 \mathrm{~km})$. Contudo, o teor de sólido deverá ser maior que o líquido, neste caso a estação deverá tratar o resíduo antes de encaminhá-lo ao aterro. Desta forma, a ETA-JF necessitará de um sistema de secagem do lodo, o método mais econômico, segundo a pesquisa de Sousa et al. (2014) seria o tratamento geotêxtil com gasto de implantação em R $\$ 63.733,00$ (valor na época do estudo). Outro fator, problemático para o uso em aterro é a sua vida útil que está projetada para 25 anos (Furtado, 2010). Pois caso, não se destine esse resíduo para o aterro sua vida útil pode ser mantida (25 anos) ou mesmo aumentar. Com isso, mesmo a distância sendo menor, não será boa opção, pois poderá comprometer a vida útil do aterro.

Além do custo de transporte foi verificado a quantidade do resíduo que poderá ser utilizado em cada sistema de aproveitamento. O lançamento em ETE seria uma boa opção devido ao uso de $100 \%$ do lodo gerado, além de ter distância próxima, fatores importantes para escolha. Outro ponto interessante é a previsão de ampliação desta ETE para tratamento de 100\% do esgoto da região norte, com isso, poderá em projeto prever maior vazão para o recebimento do lodo da ETA. Assim torna-se boa opção no destino final do lodo, ainda que se tenha que avaliar o destino final a ser dados para ambos os lodos ETA e ETE ao final do tratamento da ETE.

Tabela 4. Custo de transporte de disposição final do lodo.

\begin{tabular}{cccc}
\hline Tipo de tratamento & Local & $\begin{array}{c}\text { Distância da ETA ao } \\
\text { destino final }(\mathbf{K m})\end{array}$ & Valor do frete ao local $^{\mathbf{2}}$ \\
\hline Lançamento em ETE & ETE Barbosa Lage & 7,77 & $\mathrm{R} \$ 51,03$ \\
\hline Aterro sanitário & $\begin{array}{c}\text { Bairro Dias } \\
\text { Tavares }\end{array}$ & 2,81 & $\mathrm{R} \$ 18,46$ \\
\hline Confecção de tijolo & Bairro Nova Era & 5,03 & $\mathrm{R} \$ 33,05$ \\
\hline Disposição em viveiro & Bairro Humaitá & 11,38 & $\mathrm{R} \$ 74,77$ \\
\hline & & Fonte: Autoria Própria
\end{tabular}

Para confecção de tijolo solo-cimento com adição de 5\% de lodo será necessário a quantidade de $0,135 \mathrm{~kg}$ de lodo da ETA para a fabricação de 1 unidade (Cordeiro, 2018). Assim a quantidade de lodo gerado na estação seria grande para a empresa poder suprir, visto que a demanda pela fabricação do produto não é de larga escala e o espaço físico da empresa é pequeno.

No entanto para o cultivo de planta considerando o preparo de $1 \mathrm{~kg}$ dos substratos, na melhor proporção de $50 \%$, teria o uso de $0,5 \mathrm{~kg}$ de lodo. Além disso, o lodo poderá ser utilizado na sementeira e até no preparo para venda como substrato. Como a ETA está localizado próximo a áreas rurais, seria boa alternativa para a distribuição do lodo, neste caso, para a quantidade de 47 Ton. de lodo, teria a produção de 94.000 mudas considerando um saco de $1 \mathrm{~kg}$.

Conclui-se que o lodo gerado nas estações de tratamento de água apresenta uma grande quantidade de resíduos que são descartados de forma incorreta prejudicando o meio ambiente. Sendo

${ }^{2}$ Calculado com base no site: https://trucao.com.br/calculo-frete/ 


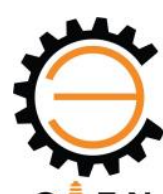

C E N

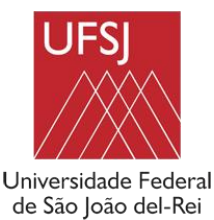

importante que as ETAs busquem meios que possam minimizar ou eliminar os impactos ambientais produzidos pela disposição incorreta do lodo. Diante da pesquisa realizada, verifica-se que os maiores potenciais de uso são: em viveiros, disposição em ETE, aterro sanitário, confecção de tijolos e material cerâmico. Alguns usos trazem mais desvantagens sendo: incineração e disposição no solo. Destacando que cada local deve analisar a melhor alternativa para sua realidade.

Para a ETA- JF, deve-se ter um tratamento de secagem do lodo da ETA, pois na maior parte das alternativas é necessário que se tenha um teor de sólidos elevado. Portanto, as duas maiores potencialidades de uso são na fabricação de tijolo e como substrato em mudas de viveiro, contudo são as mais onerosas e que não levam a $100 \%$ do uso do lodo. No entanto, poderia se pensar na destinação do lodo para ambos os destinos de forma a se chegar nos $100 \%$. As alternativas de aterro sanitário e disposição na ETE, ambas são mais econômicas, contudo, geram um passivo, redução da vida útil do aterro e tratamento de volume maior de lodo na ETE.

\section{AGRADECIMENTOS}

Ao Programa de Pós-graduação em Ambiente Construído, a Universidade Federal de Juiz de Fora e Coordenação de Aperfeiçoamento de Pessoal de Nível Superior pela bolsa concedida.

\section{DIREITOS AUTORAIS.}

Os autores são os únicos responsáveis pelo conteúdo das informações contidas neste artigo.

\section{REFERÊNCIAS}

ACHON, C.L e CORDEIRO, J.S. Destinação e disposição final de lodo gerado em ETA - LEI 12.305/2010. ASSEMAE - Associação Nacional dos Serviços Municipais de Saneamento. XIX Exposição de Experiências Municipais em Saneamento. Maio - Poços de Caldas/MG, 2015.

ACHON, C.L e CORDEIRO, J.S. Riscos da destinação de lodos de ETAs - LEIS 9.605/1998 e 12.305/2010. ASSEMAE - Associação Nacional dos Serviços Municipais de Saneamento. XVII Exposição de Experiências Municipais em Saneamento. Maio - Vitória/ES, 2013.

ALMEIDA, A.P.V., CARVALHO, K.Q., PASSIG, F.H. Caracterização quantitativa do lodo gerado na estação de tratamento de água de Campo Mourão PR. Revista eletrônica Técnico-Científica do IFSC, Vol.1, n 1, p.36-40, 2010.

ANDRADE, C.F., SILVA, C.M. e OLIVEIRA, F.C. Gestão ambiental em saneamento: uma revisão das alternativas para tratamento e disposição do lodo de ETA e seus impactos na qualidade das águas. V Congresso Brasileiro de Gestão Ambiental. IBEAS - Instituto Brasileiro de Estudos Ambientais. Belo Horizonte/MG, 2014.

ANDRADE, P.S. Avaliação do impacto ambiental da utilização de resíduos de estações de tratamento de água em indústrias de cerâmica vermelha: Estudo de caso. Dissertação de Mestrado. Universidade Estadual de Campinas, 269 p., 2005.

ARAÚJO, R.N. e SILVEIRA, L.R. Reaproveitamento de resíduos de ETA e ETE em obras de engenharia. Revista Técnica e Tecnólogia (Ciência, Tecnologia, Sociedade), Vol 1, n 2, 2017.

ASSOCIAÇÃO BRASILEIRA DE NORMAS TÉCNICAS. NBR 10.004 - Classificação de Resíduos Sólidos. Rio de Janeiro, ABNT, 2004. 
AUGUSTO, J. Lodo de estação de tratamento de água na composição de substratos para produção de mudas de plantas da caatinga. Dissertação de Mestrado em Engenharia Civil e Ambiental. Universidade Federal da Paraíba, 79 p., 2016.

BIDONE, F.; SILVA, A.P. e MARQUES, D.da M. Lodos produzidos nas estações de tratamento de água (ETAs): desidratação em leitos de secagem e codisposição em aterros sanitários. Resíduos sólidos do saneamento: processamento, reciclagem e disposição final. Cleverson Vitório Andreoli (coordenador). Rio de Janeiro: Rima, ABES, 2001. Prosab Cap.9 p.215-244.

BOTERO, W.G.; SANTOS, A.DOS; OLIVEIRA, L.C.DE e ROCHA, J.C. Caracterização de lodo gerado em estações de tratamento de água: perspectivas de aplicação agrícola. Revista Quim. Nova, Vol. 32, n 8, p.2018-2022, 2009.

BRASIL (1998). Lei № 9.605 de 12 de fevereiro de 1998. Sanções penais e administrativas erivadas de condutas e atividades lesivas ao meio ambiente. Congresso Nacional, Brasília, DF, 2010.

BRASIL (2010). Lei No 12.305 de 02 de agosto de 2010. Política Nacional de Resíduos Sólidos. Congresso Nacional, Brasília, DF, 2010.

COELHO, R.V., TAHIRA, F.S., FERNANDES, F., FONTENELE, H.B., TEIXEIRA, R.S. Uso de lodo de estação de tratamento de água na pavimentação rodoviária. Revista eletrônica de engenharia civil (REEC), Vol. 10, $\mathrm{n}^{\circ}$ 2, p.11-22, 2015.

Companhia de Saneamento Municipal de Juiz de Fora (CESAMA). Disponível em:<http://www.cesama.com.br/?pagina=resanto>. Acesso em: 05 abr. 2019.

CORDEIRO, R.DAS. Resíduos de estação de tratamento de água na produção de tijolos ecológicos: inovação e gestão industrial sustentável. Dissertação de Mestrado em Engenharia Ambiental. Instituto Federal de Educação, Ciência e Tecnologia Fluminense, 54 p., 2018.

CRUZ, C.L.B.M. Estudo sobre a viabilidade de incorporação do lodo de estação de tratamento de água no substrato para produção de espécies nativas da Mata Atlântica (Brasil). Dissertação de Mestrado em Engenharia Ambiental. Universidade do Estado do Rio de Janeiro, p.138, 2018.

FERREIRA, A.C.S., SILVA, J.B.G., PEREIRA, R.O. e OLIVEIRA, A.P.S. Avaliação do desenvolvimento do capim Tifton cultivado em latossolo adubado com lodo de ETA. Revista Internacional de Ciências, Vol. 07, nº 01, p.64-83, 2017.

FERREIRA, I.L.DEL.; ARRUDA, A.T.DAS.; CALFAS, J.F.; TORQUATO, R.DAS. e SILVA, A.C. Aproveitamento do lodo da estação de tratamento de água (ETA) para crescimento de mudas florestais e frutíferas. V Seminário Internacional em Ciências do ambiente e Sustentabilidade na Amazônia, 2018.

FURTADO, Aline. Novo Aterro sanitário de Juiz de Fora começa a operar. Acessa.com, Juiz de Fora, abr. de 2010. Disponível em: <https://www.acessa.com/cidade/arquivo/noticias/2010/04/09aterro_sanitario/>. Acesso em 11 de jul. 2019.

GONÇALVES, F.; SOUZA, C.H.U.DE; TAHIRA, F.S.; FERNANDES, F. e TEIXEIRA, R.S. Incremento de lodo de ETA em barreiras impermeabilizantes de aterro sanitário. Artigo Técnico. Revista DAE, 2017.

GUIMARÃES, N.C. e PÁDUA, V.L. Avaliação de parâmetros físico-químicos para recuperação de sulfato de alumínio dos resíduos gerados em uma estação de tratamento de água. $23^{\circ}$ Congresso Brasileiro de Engenharia Sanitária e Ambiental, 2005.

JANUÁRIO, G.F. e FILHO, S.S.F. Planejamento e aspectos ambientais envolvidos na disposição final de lodos das estações de tratamento de água da região metropolitana de São Paulo. Revista Eng. Sanit. Ambient, Vol. 12, n 2, p. 117-126, 2007. 
KITCHENHAM, B. A. and CHARTERS, S. Guidelines for performing systematic literature reviews in software engineering. Technical Report, Vol. 2., n³, 2007.

LOPES, J.C. e SERRA, J.C.V. Adensamento mecânico e desidratação do lodo da ETA-6 por filttro prensa. Engenharia Ambiental, Vol. 13, n 1, p.126-132, 2016.

MARGEM, J.I. Caracterização e incorporação de lodo de decantação de estação de tratamento de água (E.T.A.) em cerâmica vermelha. Dissertação de Mestrado ao Centro de Ciência e Tecnologia. Universidade Federal Norte Fluminense Darcy Ribeiro, 83 p, 2008.

MARGUTI, A.L. Efeito do recebimento de lodos oriundos de estações de tratamento de água nos processos de tratamento de esgotos por lodos ativados convencional. Dissertação de Mestrado Engenharia Hidráulica e Ambiental. Escola Politécnica da Universidade de São Paulo, 146 p., 2012.

MARGUTI, A.L., FERREIRA FILHO, S.S., PIVELI, R.P. Full-scale effects of addition of sludge from water treatment stations into processes of sewage treatment by conventional activated sludge. Journalof Environmental Management, Vol. 215, p.283-293, 2018.

MATINS, A.R.; NETO, T.M.G.; JARDER, J.; GUIMARAES, A.; BATISTA, P.DOS S. e LIMA, M.B.DE. Estudo da resistência mecânica em blocos de solo cimento, com resíduos inorgânicos na sua composição: O caso do lodo calcinado a $900^{\circ}$ e o lodo seco da estação de tratamento de água. VII JICE. Instituto Federal do Tocantins, 2016.

MENDES, R.L; FILHO, S.S.F; SCIAN, J.B. Adensamento mecânico de lodos gerados em estações de tratamento de água. In: $21^{\circ}$ Congresso Brasileiro de Engenharia Sanitária e Ambiental, 2001a.

MONTIBELLER, I. e GIRARDI F. Tratamento e destinação final do lodo oriundo da estação de tratamento de água de uma indústria de beneficiamento têxtil. XXII Congresso Brasileiro de Engenharia Química, 2018.

MOREIRA, R.C.A.; GUIMARÃES, E.M.; BOAVENTURA, G.R.; MOMESSO, A.M. e LIMA, G.L.DE. Estudo geoquímico da disposição de lodo de estação de tratamento de água em área degradada. Revista Quim. Nova, Vol. 32, n 8, p.2085-2093, 2009.

NETO, A.F. Utilização de lodo de estação de tratamento de água na produção de mudas de árvores com ocorrência no cerrado. Dissertação de Mestrado em Engenharia do Meio Ambiente. Universidade Federal de Goiás, 97 p., 2011.

OLIVEIRA, A.P.S. Avaliação dos atributos de um latossolo adubado com lodo de estação de tratamento de água. Monografia. Universidade Federal de Juiz de Fora. Curso de Engenharia Ambiental e Sanitária, 2015.

OLIVEIRA, A.P.S., SILVA, J.B.G., PEREIRA, R.O. e SANTOS, A.S.P. Avaliação dos adubado com lodo de estação de tratamento de água. Revista Internacional de Ciência, Vol. 5, no 2, 2015.

OLIVEIRA, I.Y.Q. e RONDON, O.C. Diagnóstico da gestão de lodo de estação de tratamento de água em Mato Grosso do Sul. Interações, Vol. 17, n 4, p. 687-698, 2016.

OLIVEIRA, L.G.S. Utilização do lodo gerado no tratamento de água como componente na fabricação de tijolos cerâmicos. V Simpósio sobre Resíduo Sólido, 2017.

PAIVA, G.S., MOREIRA, V.T.G., SOARES, A.F.S. Lodo de estação de tratamento de água (LETA): resíduo ou insumo? VII Congresso Brasileiro de Gestão Ambiental. IBEAS - Instituto Brasileiro de Estudos Ambientais, 2016.

PAIVA, M.W e PARREIRA, R.L.T. Resíduos das estações de tratamento de água (ETA). Linguagem Acadêmica, Vol. 2, nº 2, p. 83-96, 2012. 
PATRIZZI, L.J.; REALI, M.A.P. e CORDEIRO, J.S. Redução de volume de lodo gerado em decantadores de estações de tratamento de água, utilizando espessamento por flotação e por gravidade. In: $20^{\circ}$ Congresso Brasileiro de Engenharia Sanitária e Ambiental, 1999.

PAZ, E.C.S.; VIEIRA, I.C.A.; SANTOS, M.L.G.; SILVA, G.G.; QUEIROZ, S.C.B.; PASCHOALA, C.F.P.R.; OLIVEIRA, L.R.A. Diagnóstico de produção de lodo na estação de tratamento de água em Palmas - TO. Revista de Engenharia e Tecnologia, Vol. 10, $\mathrm{n}^{\circ}$ 1, p. 80-87, 2018.

PAZ, L.P.S. Modelo conceitual de seleção de tecnologias de tratamento de água para abastecimento de comunidades de pequeno porte. Tese. Universidade de São Paulo, 398 p., 2007.

PEIXOTO, G.J. Avaliação da Aplicação de Lodo de ETA no Adensador de Lodo de uma ETE de Lodos Ativados. Dissertação de Mestrado em Engenharia Civil. Universidade estadual Paulista "Júlio de Mesquita Filho", 149 p., 2008.

PEREIRA, T.M., GOMES, M.H.R., PEREIRA, R.O. Estimativa final da produção de lodo em estações de tratamento de água: estudo de caso. XI Simpósio de Recursos Hídricos do Nordeste, 2012.

PEREIRA, V.E. Disposição de lodo adensado de ETA em ETE com tratamento primário quimicamente assistido. Dissertação de Mestrado em Engenharia Civil, Arquitetura e Urbanismo. Universidade Estadual de Campinas, 170 p., 2011.

Plano de saneamento básico de Juiz de Fora. Diagnóstico dos serviços de abastecimento de água $\begin{array}{lllll}\text { potável. } & \text { Produto } & \text { 02 Julho } & 2013 . & \text { Disponível }\end{array}$ em: $<$ http://www.planodesaneamento.pjf.mg.gov.br/pdf/tomo_ii_diagnostico_agua.pdf $>$. Acesso em: 05 abr. 2019.

PORRAS, A.C; ISAAC, R.L e MORITA, D. Incorporação do lodo das estações de tratamento de água e agregado reciclado de resíduo da construção civil em elementos de alvenaria - tijolos estabilizados com cimento. Ciência E Ingeniería Neogranadina, Vol. 18, nº 2, p. 5-28, 2008.

RUBIM, C. Os desafios do tratamento de lodo. Revista TAE, especializada em tratamento de água e efluentes. Ago. 2013. Disponível em: 〈http://www.revistatae.com.br/6376-noticias>. Acesso em: 02 de jun. 2019.

RIBEIRO, F.L.M. Quantificação e caracterização química dos resíduos da ETA de Itabirito-MG. Dissertação de Mestrado em Engenharia Ambiental. Universidade Federal de Ouro Preto, 136p, 2007.

RICHTER, C.A. Tratamento de lodos de estações de tratamento de água. São Paulo: Blucher, 2001.

ROCHA, D.N.; SOUZA, A.E.DE; QUEIROZ, L.M.DE e PONTES, C.A. Utilização do lodo da estação de tratamento de água na produção de mudas de eucalipto. Revista Agrogeoambiental, Pouso Alegre, Vol.7, n³, p.11-20, 2015.

RODRIGUES, F.N. Caracterização dos resíduos da estação de tratamento de água da UFLA e aproveitamento na confecção de tijolos de solo-cimento. Dissertação de Mestrado Acadêmico. Universidade Federal de Lavras, 118 p, 2015.

RODRIGUES, L.P. e HOLANDA, J.N.F. Influência da incorporação de lodo de estação de tratamento de água (ETA) nas propriedades tecnológicas de tijolos solo-cimento. Cerâmica, Vol. 59, $\mathrm{n}^{\mathrm{o}} 352$, p. 551-556, 2013.

SANTOS, G.Z.B., MELO FILHO, J.A., MANZATO, L. Perspectivas de aplicações tecnológicas de lodo gerado no processo de tratamento de água dos rios Negro e Solimões. Revista Matéria, Vol. $23, n^{\circ} 03,2018$. 


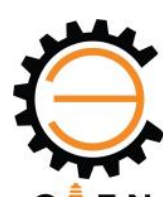

C $\mathbf{E} \mathbf{N}$

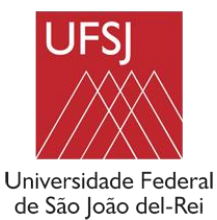

SIDRA-Sistema IBGE de Recuperação Automática, 2010. Disponível em: <https://sidra.ibge.gov.br/Tabela/1755>. Acesso em: 18 abr. 2019.

SILVA, A.S., HEMSI, P.S. Efeito do teor de sólidos na resistência ao cisalhamento de um lodo de ETA visando seu uso em cobertura diária de aterros sanitários. XIX Congresso Brasileiro de Mecânica dos Solos e Engenharia Geotécnica Geotécnica e Desenvolvimento Urbano (COBRAMSEG), 2018.

SILVA, C.A. DA; SILVA, A.A. DA; NISHI, L.; SILVA, M.F.DA; REZENDE, L.C.S.H. e BERGAMASCO, R. Incorporação de lodo de tratamento de água na fabricação de painéis de madeira aglomerada. Revista Engevista, Vol. 17, n 3, p. 398-406, 2015.

SILVA, C.A., SILVA, A. A., FREITAS, B.O., CRUZ, N.R., BORTOLOZZO, F.G., REZENDE, L.C.S.H. e BERGAMASCO, R. Estudo da incorporação de lodo de ETA em painéis de madeira aglomerada. XX Congresso Brasileiro de Engenharia Química (COBEQ), 2014.

SILVA, M.R.da. Incorporação de lodo de estações de tratamento de água (ETAs) em tijolos de solo-cimento como forma de minimização de impactos ambientais. Dissertação de Mestrado profissional. Faculdade de Aracruz, 98 p., 2009.

SILVEIRA, C.; KOGA, D.S. e KURODA, E.K. Estudo da viabilidade de disposição final dos lodos de ETAs em aterros sanitários. IX Fórum Ambiental da Alta Paulista, Vol. 9, n 11, p. 251265, 2013.

SOUSA, A.P., PEREIRA, R.O., GOMES, M.H.R., SANTOS, A.S.P. Avaliação de custos e alternativas de tratamento e disposição final dos resíduos gerados em estação de tratamento de água. XII SIBESA, XII Simpósio Ítalo-Brasileiro de Engenharia Sanitária e Ambiental, 2014.

SOUZA, C.A.DE. Adensamento mecânico e desidratação por filtro prensa de esteira de lodos gerados em estações de tratamento de água. In: $21^{\circ}$ Congresso Brasileiro de Engenharia Sanitária e Ambiental, 2001.

TEIXEIRA, S.T., MELO, W.J. e SILVA, E.T. Aplicação de lodo da estação de tratamento de água em solo degradado. Pesq. agropec. bras., Brasília, Vol. 40, n 1, p. 91-94, 2005.

TSUTIYA, M.T. e HIRATA, A.Y. Aproveitamento e disposição final de lodos de estações de tratamento de água do estado de São Paulo. $21^{\circ}$ Congresso Brasileiro de Engenharia Sanitária e Ambiental. ABES - Trabalho Técnicos, 2001.

WAGNER, L.F. e PEDROSO, K. Disposição de resíduos das estações de tratamento de Água. Revista Techno Eng. Faculdades Ponta Grossa, Vol. 1, nº 09, 2014.

WOLFF, E., SCHWABE, W.K., CONCEIÇÃO, S.V. Utilization of water treatment plant sludge in structural ceramics. Journal of Cleaner Production, Vol. 96,p.282-289, 2015.

\section{EVALUATION OF THE POSSIBILITIES OF WATER TREATMENT PLANT WASTE: CASE STUDY ETA-JF / MG}

\footnotetext{
Roberta Paulina Tertolino da Silva ${ }^{(1)}$ (roberta.silva@arquitetura.ufjf.br), Sue Ellen Costa Bottrel ${ }^{(2)}$ (sue.bottrel@ufjf.edu.br), Renata de Oliveira Pereira (renata.pereira@ufjf.edu.br) ${ }^{(3)}$

${ }^{(1)}$ Federal University of Juiz de Fora (UFJF). Postgraduate Program in Built Environment. Rua José Lourenço Kelmer, São Pedro, Juiz de Fora / MG.

${ }^{(2,3)}$ Federal University of Juiz de Fora (UFJF). Department of Sanitary and Environmental Engineering Postgraduate Program in Built Environment. Rua José Lourenço Kelmer, São Pedro, Juiz de Fora / MG
} 
ABSTRACT:The growing demand for drinking water due to the population increase has contributed significantly to the expansion of waste produced in water treatment plants (ETA). Much of this material is destined for water courses, impacting the environment. This work aims to carry out a systematic review on the generation of ETA sludge in Brazil and alternatives to the final destination for reuse, presenting a case study of ETA-JF. The methodology was based on the systematic mapping, having as research source the national and international data platforms. The results obtained provided a reflection on the treatment options and the reuse of waste from the ETAs, as well as how to evaluate the quantity of the volume generated and among the alternatives to verify which method would be most efficient. It is concluded that the way of reuse for the ETA under study could be a viable option and that it will bring great benefits to the environment.

KEYWORDS: Water Treatment Plant, WTP sludge, Use of ETA waste. 